I. P. A. Morais • M. R. S. Souto • A. O. S. S. Rangel

\title{
A flow system with in-line blank correction applied to the spectrophotometric determination of total iron and chromium (VI) in wastewaters
}

Keywords Flow system - Total iron - Chromium (VI) · Blank correction · Wastewaters performed without system reconfiguration. Despite these advantages, the absence of confluence points in SIA results in some difficulties providing an efficient mixing between sample and reagents with different physical characteristics, or assuring a constant concentration along the whole plug [3]. Additionally, as in FIA, when the sample presents an intrinsic signal, a blank run might be necessary, which significantly decreases the sampling-rate and repeatability.

To overcome these difficulties, we propose a flow system with the propulsion device situated after the detector, and using the sample as the carrier. The selection of sample or the reagent into the manifold is carried out by an 8 -port selection valve. Therefore, the sample or sample/ buffer solutions provide the baseline; the signal increment is due to the reagent intercalation. This system was applied to the determination of total $\mathrm{Fe}$ and $\mathrm{Cr}$ (VI) in wastewaters. These determinations were previously used in FIA to demonstrate the possibility of carrying out simultaneous determinations using the sandwich technique [4]. injection analysis (FIA), introduced by Ruzicka and Hansen in 1975 [1], provided a considerable advancement in developing simple automatic methods. As an evolution to FIA, Ruzicka and Marshall proposed a methodology named sequential injection analysis (SIA) in 1990 [2], which consists of the sequential aspiration of well-defined sample and reagent zones into a holding coil by means of a multi-position valve. The flow is then reversed and the stacked zones are mixed and directed to the detector. These systems have the advantage of considerably saving reagents, and potentially allow different analysis to be

I.P.A. Morais - A.O.S.S. Rangel (两)

Escola Superior de Biotecnologia,

Universidade Católica Portuguesa,

Rua Dr. António Bernardino de Almeida,

4200-072 Porto, Portugal

e-mail: rangel@esb.ucp.pt

M.R.S. Souto

Universidade Fernando Pessoa,

Praça 9 de Abril 349, 4249-004 Porto, Portugal

\section{Experimental}

Reagents and solutions

Deionized water and analytical reagent-grade chemicals were used. Solutions were prepared with previously boiled water and were degassed in an ultrasonic bath prior to their introduction into the system. A $0.02 \%$ (w/v) ascorbic acid solution, prepared daily, was obtained by dissolution of the solid in a $3.2 \mathrm{~mol} \mathrm{~L}^{-1}$ ammonium acetate solution. Fe (III) stock solution was prepared by dissolving $\left(\mathrm{NH}_{4}\right)_{2} \mathrm{Fe}\left(\mathrm{SO}_{4}\right)_{2} \cdot 6 \mathrm{H}_{2} \mathrm{O}(1.404 \mathrm{~g})$ in a mixture of concentrated $\mathrm{H}_{2} \mathrm{SO}_{4}(20 \mathrm{~mL})$ and water $(50 \mathrm{~mL})$; after dropwise addition of $0.2 \mathrm{~mol} \mathrm{~L}-1 \mathrm{KMnO}_{4}$ solution (until a persistent pink color was obtained), the solution was diluted to $1 \mathrm{~L}$ [5]. Fe (II) stock solution was prepared as previously described without the addition of $\mathrm{KMnO}_{4}$. Working standard solutions containing Fe (III) or Fe (II) in the range $0.3-6.0 \mathrm{mg} \mathrm{L}^{-1}$ were obtained by dilution of the stock solutions in $1 \mathrm{M} \mathrm{HCl}$. A solution of $0.2 \% 1,10$-phenanthroline was also prepared.

For Cr (VI) determination, a solution of $0.075 \%$ 1, 5-diphenylcarbazide (DPC) was obtained by dissolving the solid in ethanol (5 mL) and diluting to $50 \mathrm{~mL}$ with $0.75 \mathrm{M} \mathrm{H}_{2} \mathrm{SO}_{4}$. A $10 \mathrm{mg} \mathrm{L}^{-1} \mathrm{Cr}$ (VI) stock solution was prepared by dissolving previously dried 


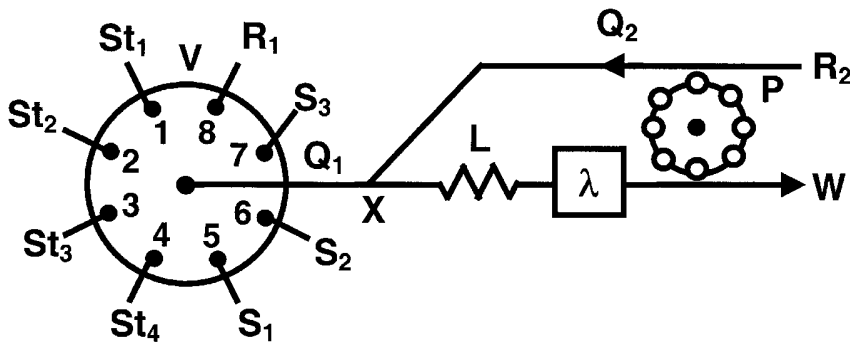

Fig. 1 Flow manifold for the determination of total iron and chromium (VI) in wastewaters. $V$ selection valve, $P$ peristaltic pump, $L$ reaction coil $(125 \mathrm{~cm}), X$ confluence, $\lambda$ spectrophotometer, $W$ waste; $S_{i}$ sample, $S t_{i}$ standard, $R_{l}$ color reagent, $R_{2} 0.02 \%$ ascorbic acid in $3.2 \mathrm{M}$ ammonium acetate solution, and sample/standard to total iron and chromium (VI) determinations, respectively, $Q_{1}$ and $Q_{2}$ flow rates

$\mathrm{K}_{2} \mathrm{Cr}_{2} \mathrm{O}_{7}$ in water. Working standards from 0.05 to $1.0 \mathrm{mg} \mathrm{L}-1$ were obtained by dilution of the stock solution.

For $\mathrm{Cr}$ (VI) determination, samples were introduced without prior treatment. Regarding total Fe, samples were digested with concentrated $\mathrm{HCl}$ and hydroxylamine [5]. Samples or digests that presented large amounts of suspended particles were filtered through a $0.45 \mu \mathrm{m}$ membrane.

Apparatus and flow procedure

A Gilson Minipuls 3 peristaltic pump, an 8-port selection valve (Valco VICI C15-3118E), and a Unicam 8625 UV/Vis spectrophotometer with a Hellma 178.710-QS flow-cell were used. All tubing were made of PTFE with $0.8 \mathrm{~mm}$ i.d. from Omnifit. A 386 personal computer (Samsung SD700) equipped with an Advantech PCL818L interface card, running homemade software written in QuickBasic 4.5, controlled the selection valve position and the pump rotation speed. Data acquisition was accomplished using the same interface card and a PCLD-8115 wiring terminal board. Signals were also recorded in a Kipp and Zonen BD 111 strip chart recorder.

The manifold developed is depicted in Fig. 1. The flow rates, the timing sequence, and the sample and reagent volumes are listed in Table 1. The sample solutions were used as the carrier, providing a baseline that corresponds to the blank reading. The signal increment, observed when a small amount of reagent is inserted, corresponds to the total $\mathrm{Fe}$ or $\mathrm{Cr}(\mathrm{VI})$ content. The $\mathrm{R}_{2}$ solution was ammonium acetate with ascorbic acid for the total Fe determination and sample for the $\mathrm{Cr}$ (VI) methodology. The measurements were taken at fixed time, $18 \mathrm{~s}$ for $\mathrm{Fe}$ and $13 \mathrm{~s}$ for $\mathrm{Cr}(\mathrm{VI})$, after the beginning of step 3 of the protocol at $510 \mathrm{~nm}$ and $540 \mathrm{~nm}$, respectively. To guarantee constant flow-rates and prevent bubble formation, the propulsion tubes were replaced when a variation of $5 \%$ in the flow-rate was observed.

\section{Results and discussion}

Development of the flow system

Total Fe determination (ferrous and ferric, suspended and dissolved) in wastewaters involves a previous digestion procedure with $\mathrm{HCl}$ and hydroxylamine. This treatment also guarantees that possible interfering species such as strong oxidizing agents, cyanide, nitrite, and polyphosphates do not interfere the spectrophotometric determination [5]. After this, the development of a flow system presents two major problems: the color of the samples (requiring a blank reading for each one), and the high acidity of the matrix, leading to a decrease in sensitivity. Additionally, it would be necessary to guarantee no $\mathrm{pH}$ differences between samples and standards.

The use of sample as a carrier enabled us to overcome the first of these problems. Regarding acidity, the continuous addition of an ammonium acetate solution to the acidic sample digest at a confluence point provided the proper in-line $\mathrm{pH}$ adjustment. After testing different ammonium acetate concentrations, the $3.2 \mathrm{M}$ solution was selected, since lower concentrations led to a decrease in sensitivity. The in-line buffer solution was capable of adjusting the $\mathrm{pH}$ of digests with approximately $1 \mathrm{M}$ acidity. This was confirmed by the similar absorbance values obtained when aspirating a $5 \mathrm{mg} \mathrm{L}^{-1}$ standard solution of $\mathrm{Fe}$ (III) prepared in $0.8,1.0$, and $1.2 \mathrm{M} \mathrm{HCl}$.

With the length of the tube connecting the selection valve to the confluence point reduced to a minimum, and the length of the reactor (L, Fig. 1) pre-set at $125 \mathrm{~cm}$, some optimization procedures were carried out. A $0.2 \%$ 1,10-phenanthroline solution was chosen as sensitivity slightly increased up to this level, and then was kept constant. After setting the reagent composition, reagent volumes of $19-76 \mu \mathrm{L}$ were tested. A $38 \mu \mathrm{L}$ reagent plug was selected as a compromise between sensitivity, repeatability, and reagent consumption.

The ascorbic acid content of the $\mathrm{R}_{2}$ solution (Fig. 1) was studied. Although no significant changes of sensitivity between $0.01 \%$ and $1.5 \%(\mathrm{~m} / \mathrm{v})$ were noticed, a minimum of $0.02 \%$ was chosen to assure that all iron present was in the ferrous state. Absorbance values for the $0.02 \%$ solution were registered by using $\mathrm{Fe}$ (III) and Fe (II) standard solutions. Results confirmed the absence of differences between both calibrations.

Flow rates of solutions aspirated through the selection valve $\left(\mathrm{Q}_{1}\right)$ and of the ammonium acetate/ascorbic acid so-
Table 1 Flow system protocol for the determination of total iron and chromium (VI) in wastewater samples

aparameters with different values for total iron and chromium (VI) determination, respectively

\begin{tabular}{|c|c|c|c|c|c|}
\hline Step & $\begin{array}{l}\text { Valve } \\
\text { position }\end{array}$ & $\begin{array}{l}\text { Operation } \\
\text { time } \\
\text { (s) }\end{array}$ & $\begin{array}{l}\text { Flow rate } \\
\left(\mathrm{mL} \mathrm{min}^{-1}\right)\end{array}$ & $\begin{array}{l}\text { Volume } \\
(\mu \mathrm{L})\end{array}$ & Description \\
\hline 1 & $1-7$ & 30 & 2.3 & 1095 & $\begin{array}{l}\text { Aspirate sample/standard through the detector } \\
\text { to create the baseline }\end{array}$ \\
\hline 2 & 8 & $2 / 4^{\mathrm{a}}$ & 1.1 & $37 / 74^{\mathrm{a}}$ & Aspirate color reagent \\
\hline 3 & $1-7$ & 40 & 2.3 & 1460 & Aspirate sample/standard through the detector \\
\hline
\end{tabular}




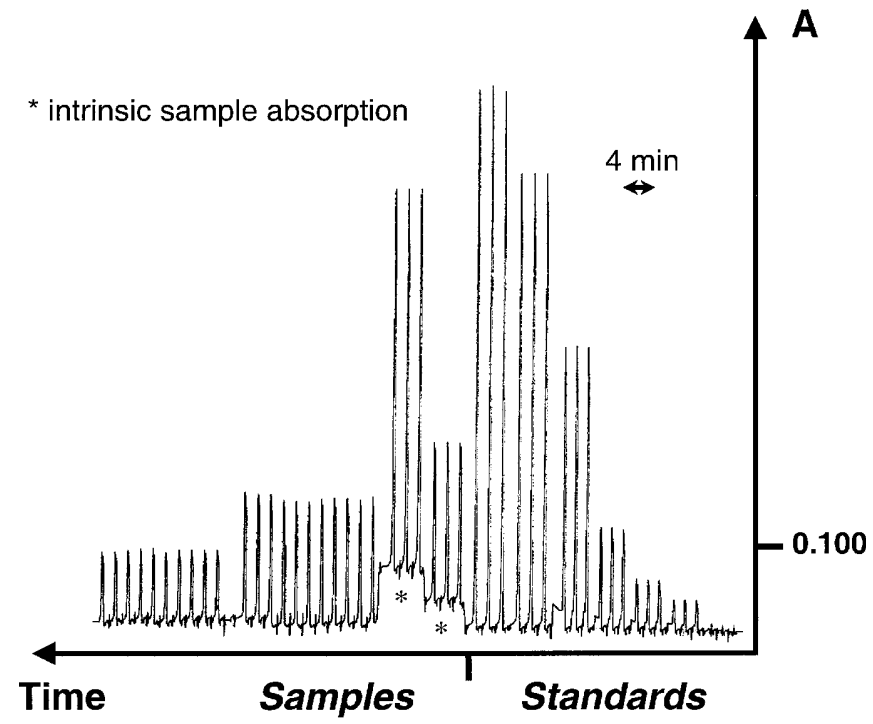

Fig. 2 Recorded output for total iron determination of a set of standards (deionized water, 0.3, 0.5, 1.0, 3.0, 5.0, and $6.0 \mathrm{mg} \mathrm{L}^{-1}$ prepared in $1 \mathrm{M} \mathrm{HCl}$ solution) and four different wastewater samples

lution $\left(\mathrm{Q}_{2}\right)$ were studied simultaneously. A proportion of two parts of sample solution to one part of ammonium acetate/ascorbic acid solution $\left(\mathrm{R}_{2}\right)$ was chosen, as a compromise between sample dilution and $\mathrm{pH}$ adjustment, enabling the highest sensitivity. The flow rates adopted were 2.3/1.2 for steps 1 and 3 , and 1.1/0.6 $\mathrm{mL} \mathrm{min}^{-1}$ for step 2 (Table 1).

Sample aspiration time was also evaluated and set to $30 \mathrm{~s}$ for step 1 (Table 1) and $40 \mathrm{~s}$ for step 3 to provide a well-defined baseline and a proper return to it (Fig. 2).

When samples with low iron concentration or complex matrix compositions were analyzed, the signal was masked by different refractive indices between solutions (Schlieren effect) [6], and the maximum absorbance did not correspond to the analytical signal. Therefore, an option was taken to perform measurements at a fixed time.

The same system configuration was used for $\mathrm{Cr}$ (VI) analysis in water. As there was no need for in-line buffering adjustment, but low detection limits were important, sample was used in both channels $\left(S_{i}\right.$ and $R_{2}$ in Fig. 1). The concentration and the volume of the reagent $\left(\mathrm{R}_{1}\right)$ were then optimized. As the reaction occurs under acidic conditions, $\mathrm{H}_{2} \mathrm{SO}_{4}$ concentrations of $0.25-1 \mathrm{M}$ (in $\mathrm{R}_{1}$ ) were studied. The $0.75 \mathrm{M}$ solution was adopted, since higher sensitivity was obtained. Concentrations of $0.025-0.12 \%$ of $1,5-$ DPC were evaluated. Sensitivity increased up to $0.075 \%$, keeping constant afterwards. The reagent volumes of $37-112 \mu \mathrm{L}$ were tested; $74 \mu \mathrm{L}$ was finally chosen, as the sensitivity had a significant increase up to this point.

The limit of quantification [7], assessed by ten consecutive injections of the blank solution $(1 \mathrm{M} \mathrm{HCl}$ for the $\mathrm{Fe}$ analysis and water for $\mathrm{Cr}$ (VI) determinations) were 0.1 and $0.03 \mathrm{mg} \mathrm{L}^{-1}$, respectively. The calibration curves obtained were: Absorbance $=0.105( \pm 0.003)|\mathrm{Fe}|+0.001( \pm 0.003)$; $r^{2}=0.9993( \pm 0.0004) ;$ Absorbance $=0.56( \pm 0.01)|\mathrm{Cr}(\mathrm{VI})|-0.001$ $( \pm 0.005) ; r^{2}=0.9993( \pm 0.0004)$. The values in parentheses correspond to the standard deviation of seven calibration curves. Possible problems associated with aspirating solutions to the systems, namely variable flow-rates and bubble formation were not significantly observed, as can be perceived by the reproducibility of the calibration curves. For both analyses, the determination rate was approximately $40 \mathrm{~h}^{-1}$.

\section{Application to water samples}

Fifteen wastewater samples were analyzed by the proposed flow procedure $\left(C_{\mathrm{s}}\right)$ and by the respective reference method $\left(C_{\mathrm{r}}\right)[5,8]$. For comparison purposes, a linear relationship $C_{\mathrm{s}}=C_{0}+S C_{\mathrm{r}}$ was established. The equation parameters and the $95 \%$ confidence limits are presented in Table 2. These results point out that there is no statistical difference between the two sets of results [9]. Relative standard deviations were lower than $3 \%$ (Table 2).

\section{Conclusions}

The methodology developed consists of a simple flow system that might be used for different spectrophotometric determinations. For each sample/standard, a blank signal is registered, allowing the correction of the intrinsic color of the sample and the refractive index due to sample matrix composition. This is accomplished using the sample as the carrier stream. Nevertheless, this approach has

Table 2 Parameters of the equation $C_{\mathrm{s}}=C_{0}+S C_{\mathrm{r}}$ for comparison of the results $\left(\mathrm{mg} \mathrm{L}^{-1}\right)$ obtained by FS $\left(C_{\mathrm{s}}\right)$ with those of the reference method $\left(C_{\mathrm{r}}\right)$, and the values for relative standard deviation (RSD) corresponding to ten consecutive determinations

\begin{tabular}{|c|c|c|c|c|}
\hline & \multicolumn{3}{|c|}{ Equation parameters } & $\operatorname{RSD}^{\mathrm{a}}(\%)$ \\
\hline Chromium (VI) & $0.01( \pm 0.02)$ & $0.98( \pm 0.03)$ & 0.9984 & $1.5(0.40), 1.4(0.73)$ \\
\hline
\end{tabular}

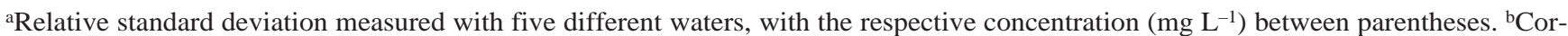

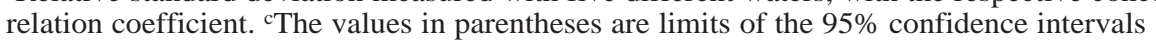


the disadvantage of consuming large amounts of sample, which is not a problem for wastewaters.

Acknowledgements I. Morais thanks Fundação para a Ciência e a Tecnologia for the grant Praxis XXI BD/20302/99.

\section{References}

1. Ruzicka J, Hansen EH (1975) Anal Chim Acta 78:145-157

2. Ruzicka J, Marshall GD (1990) Anal Chim Acta 237:329-343

3.Zagatto EAG, Rocha FRP, Martelli PB, Reis BF (2001) Pure Appl Chem 73:45-54

4. Araújo AN, Lima JLFC, Rangel AOSS, Alonso J, Bartroli J, Barber R (1989) Analyst 114:1465-1468
5. American Public Health Association (1998) Standard methods for the examination of water and wastewater (3500-Fe/Phenanthroline Method), 20th edn. American Public Health Association, Washington, DC

6. Krug FJ, Bergamin $\mathrm{F}^{\circ} \mathrm{H}$, Zagatto EAG, Jorgensen SS (1977) Analyst 102:503-508

7. Limit of Detection - A closer look at the IUPAC definition (1983) Anal Chem 55:712-724A

8. American Public Health Association (1998) Standard methods for the examination of water and wastewater (3500-Cr/Colorimetric Method), 20th edn. American Public Health Association, Washington, DC

9. Miller JC, Miller JN (1993) Statistics for Analytical Chemistry, 3rd edn. Ellis Horwood, Chichester 